\title{
Franz Kafka lido por Hannah Arendt: cultura, formação e política
}

\section{Franz Kafka read by Hannah Arendt: Culture, Education and Politics}

\section{Daiane Eccel ${ }^{*}$}

Universidade Federal de Santa Catarina (UFSC), Florianópolis, SC, Brasil

\section{Resumo}

De todos os literatos citados por Arendt, interessa-nos investigar suas relações com os escritos de Franz Kafka. Nosso objetivo neste texto é: (i) averiguar o impacto que a obra de Kafka exerce sobre Arendt e (ii) em que medida os problemas da cultura e da formação (Bildung) se põem no centro das reflexões arendtianas sobre Kafka. Para tanto, nos ocuparemos de dois textos de 1944 escritos por Arendt, a saber, O judeu como pária: uma tradição oculta e, sobretudo, Franz Kafka: uma reavaliação. Por ocasião do vigésimo aniversário de sua morte.

Palavras-chave: Arendt. Kafka. Filosofia. Estética. Formação humana.

\section{Abstract}

Of all the writers cited by Arendt, we are interested in investigating her relations with the writings of Franz Kafka. Our aim in this article is: (i) inquire the impact does the work of Kafka 
carries on the work of Arendt and (ii) how the question about culture and Bildung are at heart of Arendt's writings on Kafka. For this, we shall deal with two texts of Hannah Arendt - both 1944: The Jew as Pariah: a Hidden Tradition and Franz Kafka, a Revaluation (On the occasion of the twentieth anniversary of his death).

Keywords: Simone Weil. Time. Thought. Existence. Experience.

\section{Introdução}

É inegável que no cerne do pensamento de Hannah Arendt estão os problemas relacionados à política. Suas obras iniciais como Origens do Totalitarismo e A Condição Humana atestam esse fato, mas isso também se faz claro ao longo de toda a sua trajetória intelectual e sua última obra, A Vida do Espírito, postumamente publicada, confirma as preocupações da autora, apesar de parecer ao leitor que este escrito se ocupa apenas com os problemas relacionados à vida contemplativa. Por trás de todas as ocupações intelectuais tardias de Arendt, permanecem presentes muitas questões iniciais relativas aos seus primeiros escritos, como é o caso, por exemplo, da problemática referente à situação dos judeus, bem como seu interesse por Santo Agostinho. Importalhe, no entanto, compreender sobretudo os problemas relacionados à política, já que os dois regimes totalitários que assolaram a Europa no século passado despertaram em Arendt o anseio por compreendê-los. Se isso é claro para qualquer um que toma contato com sua obra, não é verdade, porém, que tentar compreendê-la somente a partir da problemática da política seja a única chave de leitura possível. Isso ocorre porque Arendt nunca foi uma acadêmica in stricto sensu, mas, ao invés disso, pensava a política a partir de variadas ferramentas intelectuais que não se reduziam somente aos seus conhecimentos específicos de filosofia política, ciência política, filologia ou história. Diferente disso, mobilizava diversas áreas do conhecimento a fim de pensar a política a partir de diferentes perspectivas. Neste sentido, a literatura exerce um papel de clara notoriedade. Segundo Barbara Hahn e Marie Luise 
Knott (2007, p. 15), o papel que a literatura exerce na obra de nossa autora não deve ser mitigado, já que "a forma de pensar o mundo de Kafka e Broch, Proust e Joyce fundaram seus escritos". Arendt não era somente uma assídua leitora dos textos clássicos da antiguidade ocidental, mas também da literatura de sua época - sobre a qual redigiu uma série de textos e resenhas ${ }^{1}$. Neles, a autora não somente pensa os problemas relativos à política, mas também aqueles que envolvem a cultura, a educação, a estética e a literatura em si e, por este motivo, eles podem ser considerados uma ferramenta importante para uma chave de leitura alternativa no que diz respeito ao seu framework.

Dos autores com os quais Arendt se ocupa, importa-nos tratar de suas reflexões sobre Franz Kafka, cujos personagens são utilizados por Arendt para tecer suas considerações em textos como Entre o Passado e o Futuro (2005) e A Vida do Espírito (2009). Estes textos não são meros "lugares" nos quais cabem citações, parábolas ou imagens kafkianas, mas, muito mais do que isso, suas próprias reflexões parecem surgir a partir das citações de Kafka. A relação literária de Arendt com o autor judeu é longa; segundo Knott (2005, p. 151), "nos é desconhecido quando Arendt lê Kafka pela primeira vez, mas o fez no mais tardar em seu tempo em Paris (1933-1940)". É também aparentemente relacionada à sua amizade com Walter Benjamin, que escreveu um texto em homenagem a Franz Kafka pela ocasião de dez anos de sua morte. Arendt também o fez novamente dez anos mais tarde, na passagem do vigésimo aniversário do falecimento de Kafka. Para além disso, enquanto trabalhou na Schocken Verlag² nos seus anos iniciais em Nova York, ela assumiu a tarefa, junto a Martin Greenberg, de editar e traduzir o Tagesbuch de Kafka. Segundo as instruções deixadas por Kafka a seu

ARENDT, 2007.

2 A Editora Schocken, cujo proprietário era o judeu Salman Schocken, era responsável pela tradução, edição e publicação da obra de muitos judeus na América do Norte. Benjamin, Kafka, Buber e a própria Arendt têm seus trabalhos publicados pela Schocken Verlag. Antes da ascensão do regime nacional-socialista, a editora exercia seus trabalhos em Berlim, mas, após seu fechamento, o proprietário migrou para a Palestina e posteriormente para Nova York. Nesta última, Arendt exerceu vários trabalhos e talvez o de maior destaque esteja relacionado ao espólio de Walter Benjamin; apesar de não ter sido organizado por ela, mas por Theodor W. Adorno, coube-lhe a responsabilidade de transportar os manuscritos de Benjamin do Velho ao Novo Mundo. Várias cartas entre Arendt e Schocken atestam seu envolvimento neste processo. Para tanto, conferir a troca epistolar entre Arendt e Benjamin e os documentos relativos ao seu espólio: SCHÖTTKER; WIZISLA, 2006.

Rev. Filos., Aurora, Curitiba, v. 31, n. 52, p. 304-322, jan./abr. 2019 
amigo Max Brod, sua obra deveria ser queimada após sua morte, mas Brod não o fez e os escritos kafkianos chegaram até nós. Para YoungBruhel, a Arendt coube muito esforço a fim de traduzir e organizar o escrito, já que "Max Brod organizou previamente o diário de Kafka para a publicação em alemão, mas seu trabalho foi desleixado e cada página precisava ser comparada ao manuscrito original. Apesar do trabalho ser custoso a Arendt, ela se divertia com ele" (YOUNG-BRUHEL apud BERTHEAU, 2016, p. 62).

Franz Kafka, o judeu alemão - e não tcheco, como Arendt certa

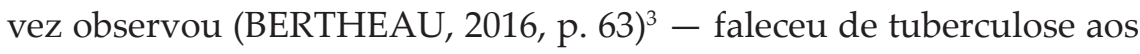
quarenta anos, deixando um generoso espólio atrás de si, que graças a Max Brod, rendeu-lhe enorme glória póstuma. Até que tal glória se consolidasse, porém, o nome de Kafka era restrito a um grupo pequeno de intelectuais que enxergavam em seus escritos uma abertura de possibilidade para refletir acerca do próprio tempo. Tal círculo, ainda minúsculo, do qual fazia parte Hannah Arendt, era restrito a intelectuais judeus da época como o primeiro marido de Arendt, Günther Anders, Walter Benjamin, bem como Gerschon Scholem. Não é curioso que o pequeno círculo que se fazia ao redor da obra de Kafka logo após sua morte fosse formado por judeus, afinal, elementos biográficos do autor contribuíam para tanto. Sua vida aparentemente medíocre de burocrata tinha como pano de fundo dois elementos famosos entre os comentários à sua obra: a sombra do pai presente em suas lembranças e uma relação interessada - ainda que bastante superficial - com a religião judaica. A Kafka interessava o estudo da Talmud, mas suas idas bastante esporádicas à sinagoga revelam o caráter quase secular com o qual lidava com seu judaísmo. O mesmo não acontece, porém, com os aspectos político e cultural da sua religião que, segundo Arendt, aparecem claramente em seu romance $O$ Castelo.

3 Arendt corrige 0 crítico de literatura norte-americano Alfred Kazin, que escreveu um texto sobre Kafka em 1946. Ela lhe escreve questionando: "Somente um pequeno detalhe: por céus! Por que o senhor pensa que ele era um 'gênio tcheco'? 0s fatos são: nasceu judeu em Praga, nunca escreveu uma única palavra na língua tcheca, mas sim, como o senhor sabe, sempre em alemão" (ARENDT apud BERTHEAU, 2016, p. 63). 
Arendt leva Kafka em alta conta ao partir de sua parábola Ele $e^{4}$ fim de refletir sobre o tempo. Este aspecto parece, como afirmam Hahn e Knott (2007), realmente fundar as bases de suas reflexões acerca da lacuna aberta entre o passado e o futuro e isso fica claro tanto pelos escritos em si, mas também por meio de fontes secundárias como a anotação em seu Denktagebuch, em 1970, acerca da "construção do tempo em Kafka", bem como da sua carta a Heidegger em 24 de setembro de 1967, na qual Arendt sugere ao seu antigo professor que se atente ao conceito de tempo em Kafka. Segundo Knott, ao se deparar com os escritos de Kafka em seu Tagesbuch, a autora se dá conta que Kafka transita livremente pelo tempo, sem se deter à sua permanente linearidade e observa ainda que se Arendt, mais tarde em 1955, afirma que a poesia de Marcel Proust pertence a um "nicht mehr", um "não mais", a obra de Kafka, ao contrário, pertence à categoria do "noch nicht", do "ainda não", já que se refere a um mundo por vir (kommende Welt) (2005, p. 154). Por outro lado, é justamente este livre trânsito de Kafka entre as categorias de tempo - antes, depois, agora - que atestam seu caráter moderno. Ao tratar da maquinaria burocrática, Kafka não poderia estar referindo a outro tempo que não o seu. O kommende Welt, o mundo que ainda estava por vir já era o mundo de Kafka. A partir da obra do autor judeu, Arendt desenvolve, portanto, um dos conceitos centrais de sua obra, a saber, o momento no qual nos encontramos - aquele que não pertence nem ao passado e nem ao futuro, já que estamos suspensos na lacuna do tempo, a partir da qual não é mais possível acessar a tradição e nem fundar uma nova. A mesma parábola aparece em A Vida do Espírito "na esperança de descobrir onde o ego pensante está temporalmente situado e se a sua incansável atividade pode ser temporalmente determinada" (2009, p. 224).

Estes dois escritos mais tardios atestam textualmente as influências de Kafka sobre Arendt e, embora constituam lugar central em seu pensamento, importa-nos, porém, olhar para os escritos mais antigos sobre Kafka, a saber, ambos os textos da década de quarenta e,

4 A referência a tal parábola aparece tanto no prefácio de Entre o Passado e o Futuro (2005) quanto na parte referente ao pensar em A Vida do Espírito (2009). 
sobretudo, à nova apreciação que ela faz de sua obra: O judeu como pária: uma tradição oculta e Franz Kafka: uma reavaliação. Por ocasião do vigésimo aniversário de sua morte - ambos de 1944. Para tanto, partiremos das observações de Susannah Y. Gottlieb a respeito da centralidade do papel da cultura nestes escritos de Arendt ${ }^{5}$. Diferente do que ela afirma, a saber, "no centro do ensaio de Arendt sobre Kafka, o problema básico da cultura está lucidamente presente" (2007, p. XX), o problema não aparece de forma tão explícita, mas acreditamos que é possível seguir com esta perspectiva e nos interessa fazê-lo a fim de testarmos a hipótese exposta por Gottlieb, que afirma que Arendt identifica um caráter irônico de uma Bildung presente nas obras de Kafka, sobretudo em O processo. Para ela, Josef K., protagonista de O processo, está inserido em sua própria cultura e é formado (ausgebildet) por ela, mas torna-se igualmente vítima dela, na medida em que é envolvido em uma maquinaria burocrática da qual não consegue escapar.

Neste sentido, além de investigar quão fundante é o papel que a obra de Kafka desempenha sobre as reflexões de Arendt, gostaríamos também de analisar dois aspectos do pensamento de Arendt que não são comumente trazidos à baila: a cultura e a Bildung, ou o processo de formação, levando em consideração o profundo envolvimento de Arendt com os escritos de Kafka. Em última instância, no entanto - e é preciso que isso seja observado - encontra-se o aspecto que constitui sempre o pano de fundo das reflexões arendtianas: a política e a burocratização do sistema que levou a Alemanha altamente desenvolvida à maquinaria dos campos de concentração na primeira metade do século XX.

\section{Kafka de Arendt}

Para pensar acerca dos acontecimentos políticos que assolaram o século passado, Arendt encontrou seu amparo em diversas obras literárias. É necessário, portanto, nos atentarmos às companhias - não

5 Responsável pelo texto de introdução da coletânea de textos de Arendt, Reflections on Literature and Culture. 
somente físicas - mas, sobretudo literárias, com as quais Arendt escolheu permanecer e, por meio delas, pensar a política. A tese do dois-em-um socrático, o eme emauto platônico, ou o estar só comigo mesmo, não é apenas uma constatação abstrata da autora presente em $A$ Vida do Espirito, mas, mais do que isso, trata de sua própria vivência como pensadora. No diálogo de Arendt com ela mesma, faziam-se presentes muitos outros amigos e a própria forma como ela mesma pensava parecia ser literária, ou seja, livre das amarras da lógica ou das puras categorizações como é comum aos acadêmicos de profissão. É Jerome $\mathrm{Kohn}^{6}$, seu antigo assistente na New School, que conta que havia um retrato de Franz Kafka no corredor de seu apartamento que dava justamente contra a porta de entrada dele. Com isso, Kohn sugere que, ao encontrar Kafka, ela retornava, de fato, a sua casa e, embora ela não faça uso diretamente dos escritos dele para tratar das suas considerações sobre o totalitarismo, ela encontrava nele a coragem necessária para voltar os olhos ao presente e refletir sobre os acontecimentos (2011, p. 239). O Kafka de Arendt assume, portanto, um papel fundamental em sua obra: ele é aquele que a ajuda a pensar seu próprio tempo.

Em seu tributo ao vigésimo ano da morte do autor, Arendt não hesita em louvar a simplicidade e certa cotidianidade que exalam dos textos de Kafka, apesar da distopia e do absurdo estarem constantemente presentes nele. Sob o ponto de vista literário, parece não haver nada de especialmente excepcional na obra kafkiana e, segundo Arendt, esse é o aspecto que o torna marcante: "não se dedicou a nenhuma espécie de experimentalismo técnico; sem alterar de maneira alguma a língua alemã, ele a despojou de suas construções elaboradas até torná-la simples e clara, como a fala do dia-a-dia expurgada de gírias e descuidos" (2016, p. 96) ${ }^{7}$. Essa linguagem desprovida de vocabulário rebuscado e formulações ostensivas revela, por sua vez, o caráter da modernidade. Não só o conteúdo dos contos e romances de Kafka tratam de um mundo que é ou que ainda está por vir, mas também a

6 Jerome Kohn escreve o verbete Franz Kafka no Hannah Arendt Handbuch. Cf. HEUER, 2011, p. 238-240.

7 Conferir 0 texto "0 judeu como pária: uma tradição oculta" em ARENDT, 2016, p. 493-523. Em inglês o texto se encontra publicado na coletânea Reflections on Literature and Culture (2007, p. 69-90) sob o título "The Jew as Pariah: a Hidden Tradition". Em alemão o encontramos sob o título "Die verborgene Tradition - Sechs Essays", 1948. 
forma como os acontecimentos são expressos. Segundo Anne Bertheau (2016), autora de Das Mädchen aus der Fremde: Hannah Arendt und die Dichtung Rezeption, além do tipo de linguagem empregada por Kafka, outro elemento salta aos olhos de Arendt: o tipo de figura ou de personagem que surge em suas obras. A própria Arendt observa que, com exceção do protagonista, todos os outros não têm vontade própria; às vezes são tomados pela indiferença e desprovidos de qualquer espírito de ação. São nomeados, mas não têm suas características pessoais exaltadas. Em alguns casos, esse traço chega também ao próprio protagonista que, como nos é conhecido, é apresentado apenas pela inicial, como ocorre com Josef K. em O Processo, K. em O Castelo e "Ele" no pequeno conto de mesmo título, todos os três comentados por Arendt. O judeu como pária: uma tradição oculta (2016) tem como ênfase a problemática política que envolve os judeus e seu legado intelectual e cultural no Ocidente. Junto de Kafka, Heinrich Heine e Bernard Lazare compõem o argumento de Arendt que enfatiza o fato de que a cultura ocidental é, em parte, devedora de uma cultura judaica que se revelou por meio de nomes de literatos e artistas que traziam em seu conteúdo parte da realidade vivida como judeus párias - sem cair na mera autobiografia. Essa tradição, no entanto, é esquecida ou oculta. No caso específico de Kafka, Arendt enfatiza que seu personagem pária aparece em dois momentos de sua obra: Descrição de uma Luta (1985) e no celebrado O Castelo (2003). No primeiro, o judeu pária vive em uma sociedade de "ninguéns" e o desfecho sempre será trágico, afinal, ele não é reconhecido por ninguém, mas também está em meio a uma sociedade em que todos são ninguém. A situação que se impõe ao personagem de Kafka é a do absurdo da dúvida da sua própria existência, bem como da existência da sociedade em si. O desfecho da situação parece dramático em qualquer circunstância: ele será excluído, já que a sociedade "adota uma atitude de franca agressão" contra o pária ou contra os heróis kafkianos (2016, p. 514). Neste sentido, pouco importa se o personagem de Kafka vive em uma comunidade onde todos são párias ou se ele resolve buscar seu refúgio no âmbito das artes ou da natureza 
a fim de fazer uso da "faculdade contemplativa como instrumento de autopreservação" (2016, p. 514).

A respeito d'O Castelo, por sua vez, "não poderia ter sido achada uma analogia melhor para ilustrar todo dilema do moderno aspirante a judeu assimilacionista" (2016, p. 515), já que K. é, segundo Arendt, um "herói [que] é nitidamente um judeu” (2016, p. 514). O protagonista não pertence a lugar algum e a ninguém, mas mesmo assim esforça-se para fazê-lo - ainda que sem sucesso. O judeu de Kafka que se apresenta na pele de K., porém, não é o judeu que a própria Arendt critica, a saber, aquele que se contenta na medida em que se beneficia de um status quo superficial com base em benefícios econômicos e sociais ao invés de almejar direitos políticos. É por este motivo que ela intitula a parte de seu texto referente a Kafka de Kafka, o homem de boa vontade, já que seu herói, K. é este homem que se dirige ao "judeu médio de pouca importância que realmente não quer nada além dos seus direitos enquanto ser humano: casa, trabalho, família e cidadania" (2016, p. 516) - situação que descreve a verdadeira tentativa de assimilação. O romance que normalmente invade o leitor de angústia pelo fato de o protagonista nunca chegar ao castelo mostra-nos, segundo a interpretação engajada de Arendt, algo a mais do que a convencional interpretação das obras de Kafka que revelam o caráter burocrático do sistema, mas denota aqui a vontade de pertencimento a algo ou alguém por parte do protagonista. É por este motivo que Descrição de uma luta e $O$ Castelo foram colocados lado a lado, pois em ambos o protagonista se encontra em qualquer lugar que não é o dele, embora deseje fazer parte. No caso do último, porém, apesar de o leitor comum e típico não se deparar com o esperado final feliz, há, sob o ponto de vista de Arendt, uma espécie de engrandecimento moral por parte dos aldeões da vila que percebem o esforço de K.:

a própria luta que ele travou para obter algumas coisas básicas que a sociedade deve aos homens abriu os olhos dos aldeões, ou pelo menos de alguns deles. Sua história, seu comportamento lhes ensinou que a vale a pena perseguir os direitos humanos, assim como que o domínio do castelo não é lei divina e, consequentemente, pode ser atacado (2016, p. 521). 
É interessante notar que, sobretudo no que diz respeito às considerações arendtianas sobre $O$ Castelo, o caminho de argumentação escolhido por Arendt não é o mais comum, a saber, a crítica do aparato burocrático ou de um grande sistema que impede com que K. chegue, finalmente, ao castelo. Ao invés disso, porém, ela faz do protagonista o seu objeto de apreciação enfatizando a tentativa kafkiana de torná-lo "normal", já que ele deseja ser, nas palavras de Kafka, "indistinguível" junto aos demais aldeões. Em uma das passagens de seu texto, ela afirma que "uma verdadeira vida humana não pode ser levada por pessoas que se sentem destacadas das simples e básicas leis da humanidade, nem por aqueles que escolhem viver em um vácuo, mesmo que sejam levados a isso pela perseguição. A vida dos homens deve ser normal, não excepcional" (2016, p. 521). É com esse acento político conferido ao texto que Arendt ataca duas vias do judaísmo: uma que simplesmente se assimila a ponto de renunciar por completo a suas crenças e tradições e outra que insiste em se diferenciar do resto do mundo como alguém que faz parte do "povo escolhido". Neste sentido, o texto parece partir de uma perspectiva moderada de sionismo que, segundo ela, corresponde aos ideais kafkianos na medida em que ele percebeu que era necessário "abolir a posição 'anormal' dos judeus, um instrumento por meio do qual eles podem se tornar um povo como outros povos'" (2016, p. 521).

O segundo texto de 1944, Franz Kafka: uma reavaliação. Por ocasião do vigésimo ano de sua morte ${ }^{8}$ causa estranheza ao leitor na medida em que percebemos a ausência de qualquer consideração acerca do judaísmo de Kafka ou deste aspecto em seus protagonistas. O romance $O$ Castelo, no entanto, continua na berlinda e a lógica com a qual Arendt trata K., o protagonista, é a mesma: ele busca apenas viver como um homem normal, luta pelos direitos inalienáveis de cada homem e, com isso, desperta em parte o estranhamento e em parte a admiração dos aldeões.

8 ARENDT, 2008. p. 96-108. Em inglês sob o título Franz Kafka, a Revaluation (On the occasion of the twentieth anniversary of his death), publicado em 1944 na Partisan Review II. Mais tarde também se encontra escrito como “Franz Kafka, Appreciated anew", na coletânea Reflections on Literature and Culture (2007, p. 94-109). 0 texto em alemão é intitulado "Kafka, von neuem gewürdigt", de 1946 na revista Die Wandlung I. 
Se no texto anterior acerca do judaísmo Arendt havia escolhido Descrição de uma luta para comentar ao lado de O Castelo, corroborando assim, suas teses sobre o judaísmo de Kafka, neste segundo escrito ela comenta O Processo - talvez o romance mais conhecido do autor, sobre o qual, segundo ela, "já gerou uma pequena biblioteca de interpretações" (2008, p. 97). A escolha desta obra e o movimento que ela faz durante todo seu texto é calculado para que o acento recaia sobre a maquinaria burocrática moderna e as implicações disso para uma modernidade que é anunciada quase profeticamente por Franz Kafka. O objetivo de Arendt vai além de mostrar ao leitor o que é óbvio, a saber, que o pesadelo kafkiano se torna realidade ao longo do século XX. Ela lança mão de mais do que apenas uma simples associação entre a distopia assustadora que toma conta do universo kafkiano e a maquinaria burocrática associada a um "grande sistema" que se revelou ao longo do século passado. Arendt é mais sutil em suas análises ou podemos afirmar que a genialidade é de Kafka e Arendt apenas a percebeu. $\mathrm{O}$ fato é que ambos os romances comentados por Arendt não expressam um universo dualista simplório no qual os protagonistas são tratados como ingênuos e por isso são atacados pelo sistema burocrático em que, conforme se dá em O Castelo, ocorre "a substituição do governo pela administração e das leis por decretos arbitrários" (2008, p. 101), ou ainda, em as leis do sistema são tratadas como leis divinas. Diferente disso - sobretudo em O Processo e menos em O Castelo - o protagonista, Josef K., não é somente vítima, mas é ele mesmo parte da maquinaria. Neste sentido, gostaríamos de investigar em que medida a cultura na qual Josef $K$. está inserido interfere em seu processo de formação e, dessa forma, averiguar se a tese anunciada por Susannah Y. Gottlieb (2007) ${ }^{9}$, a saber, de que o tema da cultura é central na interpretação de Arendt sobre Kafka e a de que O processo é uma espécie Bildungsroman invertido, um romance de formação negativo, encontra aqui seus fundamentos.

\section{Arendt leitora de Kafka: o fracasso da Bildung?}

9 Referimo-nos à introdução de Susannah Y. Gottlieb aos textos de Arendt em Reflections on Literature and Culture. 
Em uma conferência de 1810, Karl Morgenstein define o Bildungsroman, ou o romance de formação:

Ele deve se chamar romance de formação, sobretudo e em primeiro lugar por causa do assunto, porque ele representa a formação do herói em seu começo e em seu desenvolvimento até um certo estágio de aperfeiçoamento, mas em segundo lugar também porque, exatamente através dessa representação ele também fomenta a formação do leitor, numa medida mais ampla do que em qualquer outra espécie de romance (MORGENSTEN apud MAZZARI, 2010, p. 98).

Este tipo de literatura, bastante típica do século XVIII, mas que ainda encontra exemplares na modernidade, normalmente é composta por elementos condensados em um único texto, como anuncia Mikhail Bakthin, em seu Por uma tipologia histórica do Romance, "a viagem, as provas, as tentações, a biografia ou autobiografia" (BAKTHIN apud FREITAG, 1994, p. 64), tendo como objetivo o aprendizado e a formação moral do sujeito. Sob este ponto de vista, O Castelo pode ser entendido como uma espécie de Bildungsroman na medida em que K. é um agrimensor forasteiro que chega na aldeia a fim de fazer seu trabalho, passa o romance inteiro sendo submetido a provações, envolve-se amorosamente, mas ao fim, não há redenção para K. Nos interessa, no entanto, investigar o motivo pelo qual O Processo, história cujo protagonista é outro sr. K. (Josef K.) poderia ser considerado, segundo Susannah Y. Gottlieb,

um tipo peculiar de Bildungsroman que ironicamente revela a natureza destrutiva da Bildung - ironicamente destrutiva porque o objetivo da Bildung, como Arendt indica em uma resenha anterior ${ }^{10}$, consiste no desenvolvimento de uma capacidade natural sob a orientação de uma imagem (Bild) que por sua vez, deriva de um modelo histórico-secular (Vorbild) (2007, p. XX).

10 Refere-se ao capítulo 2 da coletânea Reflections on Literature and Culture para a qual Gottlieb escreve a introdução de onde essa citação é retirada. 0 capítulo trata de uma resenha escrita por Arendt a respeito do texto de Hans Weil, The Emergence of the German Principle of "Bildung". 
Em seu mais conhecido romance, Kafka conta a história de Josef K., um bancário que é acordado em uma manhã qualquer para ser notificado judicialmente a respeito de uma acusação que ele nunca chega a conhecer ao longo de todo o livro. $\mathrm{O}$ acusado é julgado e condenado sem conhecer o motivo. $O$ fato quase banal que interessa a Arendt e que foi percebido por Gottlieb é que K. é "formado" ou "educado" (gebildet) no sistema. Ele não somente passa por uma transformação interior ao longo do processo, a ponto de realmente sentir-se culpado por algo que ele não sabe do que se trata, mas antes disso, ele é um bancário envolvido no sistema cujas leis quase inacessíveis e regras intransponíveis assumem o papel regente da vida. Se o fato de Josef K. desconhecer o motivo de seu julgamento parece ser um absurdo aos olhos de qualquer leitor, importa notar que o absurdo maior se constitui do fato de que ele passa a viver uma culpa ao longo do processo e, ao final, depois de se completar o processo de sua formação - de se efetivar o objetivo deste "peculiar" Bildungsroman -, aceita passivamente sua condenação. Ao longo do romance há inúmeras tentativas do protagonista em protestar contra a própria situação, mas a maquinaria avança e a ele parecem faltar instrumentos internos e externos para travar uma batalha contra ela. Isso porque, em parte, ele é fruto dela, moldado e guiado segundo sua própria imagem e por isso, segundo Arendt, "desempenha um papel de acordo com as regras [...] entrando no mundo da necessidade e da injustiça" (2008, p. 98). Segundo a interpretação de Arendt, Josef K. aprendeu a acreditar que o sistema era necessário e que todo o aparato que o rodeava, incluindo a burocracia em si, os funcionários que o sustentavam e ele próprio enquanto julgado eram necessários, como se todos fossem parte de uma mera engrenagem, para usar o jargão típico para este tipo de circunstância. A capacidade - aquela capacidade natural que se guia segundo um exemplo e se forma dessa maneira, ou Bildung - de todos os que jogam o jogo (inadvertidamente ou não), é utilizada em prol da maquinaria e da inevitável decadência deste tipo de mundo. Segundo Arendt: "como funcionários da necessidade, o homem se torna um agente da lei natural da ruína, com isso se degradando a um instrumento natural de destruição, a qual pode 
ser acelerada pelo uso pervertido das capacidades humanas" (2008, p. 101).

A necessidade da qual nos fala Hannah Arendt age em favor de algo que sempre ganha ares nobres e que nos joga do presente para o futuro: o progresso. A máquina denunciada por Kafka, cujas engrenagens trabalham sem se chocarem, atua a favor do progresso e há um tipo de cultura pérfida por trás que alimenta a crença na necessidade dele. Mas o argumento, aqui, não é centrado na questão do progresso; diferente disso, ao que nos parece - e isso também é notado nos breves comentários de Gottlieb - , a necessidade é o ponto que Arendt deseja criticar. É importante notar que a necessidade já é a pedra de toque da autora em outras obras, como é o caso, por exemplo, de $A$ Condição Humana (2010). Quando ela denuncia a vitória do animal laborans na modernidade, ela o faz também levando em conta o fato de que nos deleitamos em suprir nossas carências mais básicas, aquelas que nos são designadas involuntariamente pela natureza. Natureza e necessidade formam um par indissociável. Para lidar com elas, a cultura e a "faculdade suprema de criar leis" (2008, p. 101) indicam o caminho. Aí residia também, em parte, a oposição dos termos gregos phýsis e nómos. A catástrofe se dá em duas circunstâncias: ou quando simplesmente renunciamos a nossa capacidade de criar leis humanas e nos submetemos completamente ao domínio da natureza ou, como acontece no romance kafkiano, segundo a interpretação de Arendt, quando a cultura ou as leis passam a agir puramente a favor da necessidade ${ }^{11}$. Neste texto, ela faz uso da metáfora da casa para se referir à cultura. Ela é um lar criado por nós, homens, a fim de nos proteger tanto quanto possível do jugo da natureza, mas ocorre que vez ou outra abandonamos essa casa e renunciamos à capacidade de fazer leis ou de fazer coisas que

11 A despeito de toda a admiração que Arendt guarda por Kant, há um elemento no pensamento deste filósofo que parece ser incompatível com o pensamento dela: a concepção de gênio. Kant está inserido na literatura do século XVIII — estendida até 0 XIX — que discute a concepção e o papel do gênio no campo das artes. Para ele e de forma parcialmente semelhante para outros autores, como Friedrich Schiller, por exemplo, o gênio era, segundo a citação de Arendt "a disposição mental inata por meio da qual a Natureza oferece 0 comando a Arte" $(2008$, p. 97). Diferente disso, ela crê que a genialidade consiste na "disposição mental por meio da qual a Humanidade oferece o comando à arte" (2008, p. 97). Essa pequena passagem é digna de nota, já que a Humanidade toma o lugar da Natureza. 
durem no mundo. Em seu outro ensaio Crise na Cultura: sua importância social e politica (2005), Arendt afirma que

a cultura relaciona-se com objetos e é um fenômeno do mundo [...]. A cultura é ameaçada quando todos os objetos e as coisas seculares, produzidos pelo presente ou pelo passado são tratados como meras funções para o processo vital da sociedade como se aí estivessem somente para satisfazer alguma necessidade $(2005$, p. 260).

Neste sentido a cultura, que não são os objetos de arte em si, mas a forma como eles se dão no mundo, como se interpõem entre nós e, certamente, como nós nos relacionamos com eles, compõem a mundanidade do mundo, aquilo que faz do mundo nosso lugar de viver, nossa casa; aquilo que de alguma forma faz com que o planeta Terra não seja apenas um lugar qualquer de toda a galáxia, mas nosso mundo, na medida em que não apenas vivemos como animais em meio à pura natureza, mas também construímos coisas duráveis.

Todos estes elementos externos - que estão no mundo - funcionam como ferramentas no processo da Bildung, da formação humana. O que o texto de Arendt a respeito de Kafka é capaz de nos mostrar, como apontou corretamente Gottlieb em seus comentários introdutórios, é que não parece haver um caráter determinadamente positivo na cultura, já que ela pode - e assim já nos mostrou a história quando infelizmente nos deparamos com os textos de Kafka se tornando realidade - ter um caráter pérfido. Josef K. é o exemplo fictício para tanto: formado e empregado em uma cultura burocrática e funcional, já que era bancário, facilmente internalizou o processo pelo qual estava sendo julgado, aceitando morrer, pois era necessário que assim o fosse.

\section{Arendt e Kafka: ic et nunc}

Se Susannah Gottlieb está correta em afirmar que o problema da cultura se põe no centro do texto de Arendt a respeito de Kafka, é também verdade que se não trata apenas do problema da cultura por ele próprio, mas antes importa aquilo que sempre importou para 
Arendt: a política e sua tentativa de compreender, sobretudo, os acontecimentos que assolaram a Alemanha na primeira metade do século XX. Ambos os textos a respeito de Kafka são escritos em 1944, quando o conhecimento a respeito das máquinas de morte nos campos de concentração ainda não tinha vindo à público, mas mesmo assim, Arendt já estava ciente da maquinaria burocrática que havia tomado conta da Alemanha nazista no período da Segunda Guerra. Há uma certa cumplicidade na relação que Arendt estabelece com Kafka: é como se no diálogo interno que ela trava com ele - conforme bem observou Kohn (2011) - , ela conseguisse perceber que ele não tratava de qualquer mundo fictício que tivera fantasiosamente assumido ares claustrofóbicos, mas, diferente disso, tratava de seu próprio mundo, pois Kafka sabia que "um homem apanhado na máquina burocrática já estava condenado" (2008, p. 100). Embora não desejemos conduzir nossa argumentação apelando para elementos biográficos de Arendt, sabemos que esse mundo quase irreal de Kafka passou a compor a realidade de Arendt. Neste sentido, as duas interpretações que ela faz de O Castelo, embora pareçam desalinhadas, são unificadas sob este aspecto: tanto o agrimensor judeu que não tem um lugar no mundo (primeira interpretação) quanto o acento para as ordens arbitrárias que formam o ambiente quase distópico e impedem que K. seja um homem "normal" (segunda interpretação) quanto a avalanche burocrática que toma conta de Josef K. em O Processo formam o mundo no qual Arendt estava inserida no período que transcorre entre sua formação acadêmica na metade dos anos vinte, sua estadia e internação em um campo de trabalho na França, sua imigração para os Estados Unidos e seu período como apátrida naquele país. Suas palavras atestam o ocorrido: "sabemos que a construção de Kafka não foi um mero pesadelo” (2008, p. 101). Talvez por este motivo, Arendt tenha condenado veementemente o público dos anos 20 que não enxergava na burocracia e em suas grandes figuras qualquer mal aparente, mas diferente disso, conferiram a ela um certo ar de necessidade. Como consequência, as diversas interpretações a 
respeito da obra de Kafka tomaram rumos "grosseiros como a variante psicanalítica" (2008, p. 99) ${ }^{12}$.

Para Arendt, não havia em Kafka qualquer talento para prever o futuro ou tampouco de profetizar. Se assim o fosse, afirma ela, "seria uma previsão tão vulgar quanto todas as outras previsões que nos têm assolado desde o começo do século" (2008, p. 101). Ao contrário, Kafka pensa a modernidade ou simplesmente o seu tempo. O que aparentemente ocorre é que o tempo de Kafka e o tempo de Arendt são o mesmo, o presente, e é sobre ele que importa pensar. Ele "quer destruir este mundo expondo sua estrutura medonha e oculta" (2008, p. 99) e ela, compreender. Kafka parece ser, sob este ponto de vista, um bom amigo para Arendt e Jerome Kohn (2011) provavelmente está correto em afirmar que Kafka lhe dá forças para pensar sobre tudo o que aconteceu e é com ele - entre outros - que ela se sente em casa.

Ao pensar sobre o tempo, Arendt certamente se põe na companhia dos grandes mestres que intelectualmente estiveram presentes junto dela, como Santo Agostinho e Martin Heidegger, mas Marie Luise Knott está correta em afirmar que Kafka ajuda Arendt a definir suas concepções sobre o tempo. Embora Arendt pareça ter se dedicado diligentemente para escrever seu Origens do Totalitarismo e Kafka, ao contrário, com uma linguagem cotidiana "que não tem quase nada a ver com a complexidade moderna da vida interior" (2008, p. 96) escreveu as obras com quais fomos brindados, ambos partilham "temporalmente" o mesmo mundo e, neste sentido, a epígrafe de Karl Jaspers que Arendt escolheu para ilustrar seu Origens serve perfeitamente para ela e para ele: “Não almejar nem os que passaram, nem os que virão. Importa ser de seu próprio tempo" (JASPERS apud ARENDT, 2004, p. 9).

12 Arendt refere-se aqui à tradição psicanalítica a respeito da obra de Franz Kafka. 0 verbete "psicanálise" aparece no Kafka Handbuch e indica que há uma longa tradição de pesquisa a respeito das relações entre 0 autor e a psicanálise, bem como a recepção de sua obra pela vertente psicanalista. Thomas Anz, o autor do verbete, destaca as trocas intelectuais entre Kafka e 00 tto Gross, um dos conhecidos psicanalistas contemporâneos do autor. Destaca-se ainda que um dos temas mais pesquisados por parte dos especialistas são os supostos elementos psicanalíticos em obras kafkianas como "Carta ao Pai", por exemplo, bem como sua íntima relação de amizade com Max Brod (ANZ, 2010). 


\section{Referências}

ARENDT, H. Origens do totalitarismo. Trad. Roberto Raposo. São Paulo: Companhia das Letras, 2004.

ARENDT, H. Entre o Passado e o Futuro. São Paulo: Perspectiva, 2005.

ARENDT, H. Reflections on Literature and Culture. Stanford: Stanford University Press, 2007.

ARENDT, H. Franz Kafka: uma reavaliação. Por ocasião do vigésimo ano de sua morte. In: ARENDT, H. Compreender: formação, exilio e totalitarismo. Belo Horizonte: Companhia das Letras, Editora UFMG, 2008. p. 96-108.

ARENDT, H. Avida do espírito: pensar, querer e julgar. Trad. César A. de Almeida, Antônio Abranches, Helena Martins. Rio de Janeiro: Civilização Brasileira, 2009.

ARENDT, H. A condição humana. 11. ed. Trad. Roberto Raposo. Rio de Janeiro: Forense Universitária, 2010.

ARENDT, H. Escritos judaicos. Trad. Laura Mascaro, Luciana Oliveira, Thiago D. Silva. Barueri: Amarilys, 2016.

ANZ, T. Psychoanalyse. In: ENGEL, M.; AUEROCHS, B. (Hg.). Kafka Handbuch: Leben - Werk - Wirkung. Stuttgart: Metzler, 2010. p. 65-72.

BERTHEAU, A. Das Mädchen aus der Fremde: Rezeption - Reflexion - Produktion. Bielefeld: transcript, 2016.

FREITAG, B. O indivíduo em formação. 2. ed. São Paulo: Cortez, 1994.

GOTTLIEB, S. Y. Introduction. In: ARENDT, H. Reflections on Literature and Culture. Stanford: Stanford University Press, 2007. p. i-xxiii.

HAHN, B.; KNOTT, M. L. Von den Dichtern erwarten wir Wahrheit. Berlin: Matthes \& Seitz Berlin, 2007.

HEUER, W. (Org.) Hannah Arendt Handbuch: Leben-Werk-Wirkung. Stuttgart; Weimar: Metzler, 2011. p. 238-240. 
ECCEL, D.

KAFKA, F. Descrição de uma luta. São Paulo: Nova Fronteira, 1985.

KAFKA, F. O Castelo. São Paulo: Nova Cultural, 2003.

KOHN, J. Franz Kafka. In: HEUER, W. (Hg.) Hannah Arendt Handbuch: LebenWerk-Wirkung. Stuttgart; Weimar: Metzler, 2011. p. 238-240.

KNOTT, M. L. Hannah Arendt liest Franz Kafka 1944. In: ARNOLD, H. L.; HEUER, W. Hannah Arendt: Text + Kritik. München: Text + Kritik, 2005. p. 150-161.

MAZZARI, M. V. Labirintos da Aprendizagem: pacto fáustico, romance de formação e outros temas da literatura comparada. São Paulo: Editora 34, 2010.

SCHÖTTKER, D.; WIZISLA, E. Arendt und Benjamin: Texte, Briefe, Dokumente. Frankfurt: Suhrkamp, 2006.

Recebido: 09/03/2018

Received: 03/09/2018

Aprovado: 22/01/2019 Approved: 01/22/2019 